\section{International Scientific Journal Theoretical \& Applied Science}

\author{
p-ISSN: 2308-4944 (print) $\quad$ e-ISSN: 2409-0085 (online) \\ Year: $2015 \quad$ Issue: $01 \quad$ Volume: 21 \\ Published: $30.01 .2015 \quad$ http://www.T-Science.org
}

Olga A. Levina student,

Financial University under the Government of the Russian Federation (Kaluga Branch), Russia OLYA-993_2010@mail.ru

SECTION 31. Economic research, finance, innovation, and risk management.

\title{
COMPARATIVE ANALYSIS OF FEDERAL AND REGIONAL BUDGETS IN THE SOCIAL SPHERE
}

Abstract: The article presents the results of a comparative analysis of social spending at the federal and regional levels, the proportions and outlines key trends. Particular attention is paid to social policy as an important direction of public policy.

Key words: federal budget, regional budgets, budget system, social services, finance, budget.

Language: Russian

Citation: Levina OA (2015) COMPARATIVE ANALYSIS OF FEDERAL AND REGIONAL BUDGETS IN THE SOCIAL SPHERE. ISJ Theoretical \& Applied Science 01 (21): 72-75. http://dx.doi.org/10.15863/TAS.2015.01.21.12

\section{СРАВНИТЕЛЬНЫЙ АНАЛИЗ РАСХОДОВ ФЕДЕРАЛЬНОГО И РЕГИОНАЛЬНЫХ БЮДЖЕТОВ НА СОЦИАЛЬНУЮ СФЕРУ}

Аннотация: В статье представлены результаты проведенного сравнительного анализа расходов на социальную сферу на федеральном и региональном уровнях, обозначены ключевые пропорции и тенденции. Особое внимание уделено сочиальной политике как важнейшему направлению государственной политики.

Ключевые слова: федеральный бюджет, региональные бюджеты, бюджетная система, социальная сфера, финансы, бюджет.

В основе функционирования наиболее важных финансовых институтов любого современного государства находится бюджетная система, определяющая уровень экономического роста и общественного благосостояния страны. Бюджетная система, в свою очередь, представляет собой совокупность федерального бюджета, бюджетов субъектов РФ, местных бюджетов, а также бюджетов государственных внебюджетных фондов. Самым главным элементом бюджетной системы является федеральный бюджет.

Российский экономист В. Я. Иохин считает, что бюджет представляет собой соотношение объема доходов и расходов конкретного субъекта, в качестве которого может выступать государство. Автор утверждает, что федеральный бюджет является неотъемлемой частью любой бюджетной системы, обеспечивает экономическую безопасность государства и выполняет политические и социально экономические функции [2, с. 531].
Сущность бюджета отражается в двух основополагающих распределительной и контрольной.

Распределительная функция заключается непосредственно в формировании централизованных фондов и расходовании денежных средств по уровням органов власти. Благодаря этой функции денежные ресурсы концентрируются в руках государства для выполнения общегосударственных задач. С помощью бюджета государство управляет хозяйственной жизнью страны и регулирует экономическое положение. Для того, чтобы управлять экономической сферой, государство вправе менять темпы роста или спада производства, а также изменять рост капитала и влиять на уровень спроса и предложения.

Контрольная функция позволяет узнать, насколько эффективно расходуются бюджетные средства, и в каких пропорциях они распределяются. С помощью данной функции можно выявлять определенные нарушения в 
распределении денежных средств, а также предсказывать итоги проведения социально экономической политики.

Наряду с основными функциями, многие экономисты выделяют следующие:

- стимулирующая функция, которая находит свое отображение в налоговых доходах и расходах бюджета, которые действуют в качестве стимулирования экономики;

- социальная функция проявляется в социальной направленности бюджетных средств, которые направляются на поддержание всего общества, уровня образования, культуры и др.;

- функция планирования подразумевает формирование целей, задач и основных направлений бюджетной политики;

Федеральный бюджет играет главную роль при осуществлении государственной деятельности в экономической, социальной, а также политической сферах общества, выступая при этом основным рычагом влияния на развитие экономики государства [3, с. 214].

В последнее время все более актуальным становится метод программно - целевого планирования бюджетных расходов, который заключается в планировании определенных расходов бюджета в соответствии с политикой государства.

По мнению Н.Б. Ермасовой программно целевое планирование расходов бюджета представляет собой метод бюджетирования, который направлен на достижение результата. Такие программы носят временный характер, и действуют конкретный промежуток времени, затрагивая конкретно - определенные сферы деятельности государства [1, с. 47].

Программно-целевой метод планирования расходов бюджета, в частности на социальную политику, используется на протяжении многих лет в ряде стран мира: Россия, Канада, США, Япония, Корея, Австрия, Германия, Франция, Финляндия и другие. При этом основные формы, механизмы и инструменты программно-целевого подхода к планированию значительно отличаются, так как во многом зависят от исторически-сложившихся социальноэкономических условий.

В европейских развитых странах с рыночной экономикой программно-целевой метод правомерно используют также в планировании, управлении экономикой и в государственном регулировании. В экономически развитых странах (например, США) данный метод широко используется при реализации социально экономических программ, направленных на решение масштабных социальны, экономических, экологических и других проблем путем бюджетного финансирования.
В России опыт программно - целевого планирования начал накапливаться с конца 20 века при разработке комплексных программ научно - технического прогресса при составлении пятилетних планов развития страны. Однако в то время данные программы не все были успешно реализованы. В современных же условиях федеральные программы, особенно в области социальной сферы, социальной политики, имеют огромное значение и выступают в качестве инструмента повышения эффективности расходов федерального бюджета на социальную политику и во всех отраслях в целом.

Особенностью метода программно целевого планирования является прогнозирование и разработка определенных результатов путем определения основных целей, a также конкретных мероприятий для их достижения в условиях ограниченности ресурсов за назначенный промежуток времени [10, с. 9].

Исходя из содержания бюджетного послания Президента Российской Федерации о бюджетной политике в $2011-2013$ гг., необходимо отметить, что одним из приоритетных направлений расходования средств федерального бюджета является социальная сфера. В этом послании акцентируется внимание на повышении качества социальной защиты населения, а также на развитии образования, здравоохранения и социального обслуживания.

Анализ бюджетных ассигнований федерального бюджета в социальной сфере проведен по следующим по разделам «Социальная политика», «Образование», «Культура, кинематография», «Здравоохранение», «Физическая культура и спорт», «Средства массовой информации» в 2011 - 2013 гг. Так, заметно увеличились расходы по разделу 07. «Образование»: по сравнению с 2011 годом в 2013 году (плановый показатель согласно Федеральному закону от 02.12.2013 N 348 - Ф3 «О внесении изменений в Федеральный закон «О федеральном бюджете на 2013 год и плановый период 2014 и 2015 годов»»)) этот показатель увеличился на 53826774 тыс. руб. и составил 5, $28 \%$ в общей доле расходов федерального бюджета. Несколько снизились расходы на здравоохранение с 4,76 \% в 2012 году до 4,31\% в 2013 году. Это связано, по словам министра финансов РФ, с завершением определенных целевых программ по данному разделу и переводом доли расходов в региональные бюджеты.

Что касается расходов по социальной политике, то здесь наблюдалась и существует положительная и устойчивая динамика увеличения расходов: в 2012 году доля расходов по разделу 10. «Социальная политика» 
увеличилась с 28,63\% до 29,93\%, а в 2013 году составила $34,46 \%$.

Анализ динамики расходов федерального бюджета по разделу 10. "Социальная политика" и подразделам за период 2011 - 2013 гг. показал, что в целом расходы по бюджету увеличивались за указанный период. В 2013 году общая сумма расходов по данному разделу увеличилась на 831952 385, 3 тыс. руб., что в первую очередь связано с тем, что основная доля этих расходов направлена на поддержку отдельных категорий граждан, а также на осуществление целей по обеспечению населения доступным жильем, а также иной социальной помощью.

Следует отметить заметное увеличение расходов федерального бюджета по подразделу 1001. "Пенсионное обеспечение". Доля данного показателя в общем объеме расходов возросла с $68,33 \%$ в 2011 году до 71,34 \% в 2013 году. Это произошло всвязи с совершенствованием пенсионной системы РФ, и, соответственно, с улучшением положения граждан пенсионного возраста. Однако, несмотря на это, с учетом официального прогноза по динамике инфляции реальные размеры пенсий фактически сокращаются, а также наблюдается явная тенденция к увеличению граждан пенсионного возраста и фактического дефицита Пенсионного Фонда Российской Федерации, что, несомненно, оказывает влияние на величину расходов федерального бюджета по другим направлениям.

Отрицательная тенденция преобладала в сфере социального обеспечения населения (подраздел 1003), а также по разделу 1004. "Охрана семьи и детства". Несмотря на то, что общая сумма расходов по данным подразделам увеличивалась, их доля в общей сумме расходов заметно сократилась. Так, например, доля расходов на социальное обеспечение в общем объеме сократилась на 2, 39 \%, в то же время доля расходов на охрану семьи и детства сократилась на 0, 6 \% в период 2011 - 2013 гг. Принимая во внимание динамику инфляции, стоит отметить, что это довольно высокое значение сокращения данных показателей, если учесть, что в России по - прежнему большая часть населения по количеству потребляемых услуг относится к категории бедного населения, свыше 1,5 млн. детей остаются также сиротами, а количество детских смертей определяется тенденцией к увеличению.

Анализ объема финансирования государственных целевых программ из федерального бюджета показал, что объем расходов на их реализацию по фактически исполненным данным увеличился на 6,19 \% в 2013 году по сравнению с 2012 годом. Намечается также тенденция увеличения расходов на государственные программы в 2014 году на 3,08 \% по сравнению с 2013 годом. Это во многом объясняется тем, что государственная программа направлена на достижение конкретных поставленных целей в соответствии с ограниченным объемом финансовых ресурсов. В Российской Федерации в современных условиях ограниченности ресурсов, разработка целевых программ нередко приводит к приоритетности текущих проблем. Одной из таких важнейших проблем является социально - экономическое развитие государства и социальное обеспечение населения.

Проведенный ранее Балыниным И.В. анализ финансового обеспечения образования бюджетами бюджетной системы Российской Федерации показал, что это направление является приоритетным [6, с.76]. Кроме этого, расходы на финансовое обеспечение социальной сферы учитывались при проведении рейтинговой оценки субъектов Российской Федерации по уровню риска несбалансированности региональных бюджетов [7].

Наиболее актуальной в настоящий момент является проблема неготовности российского государства к каким - либо стихийным, непредвиденным происшествиям. В случае наступления последнего государство не способно в полной мере соответствовать величине непредвиденных расходов. Гораздо эффективнее было бы предупреждение таких мероприятий и их анализ.

Среди основных методов и способов стабилизации социального положения граждан с помощью расходов федерального бюджета в стране можно выделить:

- при планировании расходов федерального бюджета необходимо исходить из максимального уровня обеспечения главных потребностей человека;

- необходимо соблюдать строго целевое использование бюджетных средств в соответствии с основными приоритетными направлениями социальной политики;

- необходимо достичь максимального уровня эффективности и результативности расходов федерального бюджета (в области социальной политики);

- необходимо укрепить правовые основы социальной сферы с помощью определения и установления конкретных минимальных социальных стандартов расходов федерального бюджета.

Таким образом, для повышения эффективности расходов бюджета на социальную сферу необходимо совершенствовать бюджетную систему государства и увеличивать объем расходов, финансируемых на социальную сферу для повышения уровня жизни населения и 
реализации социальной политики. Важным направлением в совершенствовании бюджетного законодательства в сфере реализации социальной политики необходимо разработать нормативно правовую базу, которая будет регламентировать определенную систему оценки и определения эффективности бюджетных расходов, а также процедуры контроля над эффективностью расходов.

Научное исследование проведено под руководством кафедры - «Финансы и кредит», Калужский филиал Финансового университета при Правительстве Российской Федерации, Россия.

\section{References:}

1. Ermasova NB (2009) Finansyi: Konspekt lektsiy. - Moscow. -pp. 169.

2. Iohin VY (2009) Ekonomicheskaya teoriya: Uchebnik. - Moscow: Ekonomist, pp. 861.

3. Polyak GB (2009) Byudzhetnaya sistema Rossii: Uchebnik. - Moscow: Yuniti - Dana, 2009. - pp. 703.

4. Sergienko NS (2011) Organizatsiya ispolneniya byudzheta: uchebnoe posobie. N.S. Sergienko. Kalu-ga: izd-vo OOO «Vash dom'», pp. 232.

5. Balyinin IV (2014) Finansovoe obespechenie sotsialnoy sferyi v Kaluzhskoy oblasti v 20082016 godah. Tsennosti i interesyi sovremennogo obschestva. Ekonomika i upravlenie. pp. 66-69.

6. Balyinin IV (2013) Obrazovanie kak prioritetnoe napravlenie rashodov byudzhetov byudzhetnoy sistemyi Rossiyskoy Federatsii. Chelovek v XXI veke Materialyi VIII Mezhdunarodnoy nauchno-prakticheskoy konferentsii prepodavateley i studentov. Obrazovatelnyiy konsortsium "Srednerusskiy universitet", NOU VPO "Srednerusskiy gumanitarno-tehnologicheskiy institut", TOO
"Kompyuternyiy tsentr LIK" g. Rudnyiy, Respublika Kazahstan "Rudnenskiy industrialnyiy institut" Respublika Kazahstan. pp. 75-76.

7. Balyinin I (2014) Reytingovaya otsenka sub'ektov Rossiyskoy Federatsii po urovnyu riska nesbalansirovannosti regionalnyih byudzhetov (na osnove razrabotannoy modeli) RISK: Resursyi, informatsiya, snabzhenie, konkurentsiya. 2014. \# 3. pp. 104-109.

8. Ryabova IS, Basova NV (2008) Byudzhetnoe finansirovanie otrasley sotsialnoy sferyi $\mathrm{V}$ Rossiyskoy Federatsii. Audit i finansovyiy analiz. 2008. \# 3. pp. 256-259.

9. Ivanova IA, Murzaeva OV (2012) Kolichestvennyie parametryi sistemyi finansirovaniya zdravoohraneniya $\mathrm{v}$ Rossii. Nauchnoe obozrenie. 2012. \# 2. pp. 527-537.

10. Miheev VV (2012) Kto i kak otsenit effektivnost byudzhetnyih rashodov. Zhurnal «Byudzhet». - 2012. - \#10. Available: http://bujet.ru/article/204015.php (Accessed: 15.01.2015). 